\title{
Undetectable haptoglobin is associated with major adverse kidney events in critically ill burn patients
}

François Dépret ${ }^{1,2}$, Chloé Dunyach ${ }^{1}$, Christian De Tymowski ${ }^{1}$, Maïté Chaussard ${ }^{1,2}$, Aurélien Bataille ${ }^{1,2}$, Axelle Ferry ${ }^{1,2}$, Nabila Moreno ${ }^{3}$, Alexandru Cupaciu ${ }^{1,2}$, Sabri Soussi ${ }^{1,2}$, Mourad Benyamina $^{1,2}$, Alexandre Mebazaa 1,2,4,7, Kevin Serror ${ }^{1,2}$, Marc Chaouat ${ }^{1,2}$, Jean-Pierre Garnier ${ }^{3}$, Romain Pirracchio ${ }^{5,6}$, Matthieu Legrand ${ }^{1,2,4,7^{*}}$ and for the PRONOBURN group

\begin{abstract}
Background: Intravascular haemolysis has been associated with acute kidney injury (AKI) in different clinical settings (cardiac surgery, sickle cell disease). Haemolysis occurs frequently in critically ill burn patients. The aim of this study was to assess the predictive value of haptoglobin at admission to predict major adverse kidney events (MAKE) and AKl in critically ill burn patients.

Methods: We conducted a retrospective, single-centre cohort study in a burn critical care unit in a tertiary centre, including all consecutive severely burned patients (total burned body surface $>20 \%$ and/or shock and/or mechanical ventilation at admission) from January 2012 to April 2017 with a plasmatic haptoglobin dosage at admission.

Results: A total of 130 patients were included in the analysis. Their mean age was 49 (34-62) years, their median total body surface area burned was 29\% (15-51\%) and the intensive care unit (ICU) mortality was 25\%. Early haemolysis was defined as an undetectable plasmatic haptoglobin at admission. We used logistic regression to identify MAKE and AKI risk factors. In multivariate analysis, undetectable haptoglobin was associated with MAKE and AKI (respectively, OR 6.33, 95\% Cl 2.34-16.45, $p<0.001$; OR 8.32, 95\% Cl 2.86-26.40, $p<0.001$ ).

Conclusions: Undetectable plasmatic haptoglobin at ICU admission is an independent risk factor for MAKE and AKI in critically ill burn patients. This study provides a rationale for biomarker-guided therapy using haptoglobin in critically ill burn patients.
\end{abstract}

Keywords: Haptoglobin, Intravascular haemolysis, Acute kidney injury, Burn patients, Major adverse kidney event

\section{Background}

Acute kidney injury (AKI) during an intensive care unit (ICU) stay is associated with increased mortality and morbidity $[1,2]$. The pathophysiology of AKI in critically ill patients remains poorly understood. Preventive or curative strategies for AKI are lacking and urgently needed. In the specific population of critically ill burn patients, the prevalence of acute AKI has

\footnotetext{
* Correspondence: matthieu.legrand@aphp.fr

${ }^{1}$ Department of Anesthesiology and Critical Care and Burn Unit, Groupe Hospitalier St-Louis-Lariboisière, Assistance publique - Hôpitaux de Paris, Paris, France

${ }^{2}$ Université Paris Diderot, Paris, France

Full list of author information is available at the end of the article
}

been reported to be as high as $53 \%$, with mortality rates ranging from $35 \%$ to $70 \%$ [3-5]. Although haemodynamic alterations, including hypovolaemic shock and low cardiac output, may precipitate the development of AKI [6], other factors are likely to participate [7].

Among the factors contributing to AKI in critically ill burn patients, intravascular haemolysis is a potential candidate. Severe burns have been associated with haemolysis at the early stage of injury $[8,9]$. Haemolysis has also been described as a strong causal factor for AKI in other situations such as sickle cell disease $[10,11]$ or after cardiopulmonary bypass for cardiovascular surgery [12, 13]. The pathophysiology 
of renal toxicity is complex and multifactorial, involving (1) cell-free haemoglobin ( $\mathrm{fHb}$ ), which is a scavenger of nitric oxide (NO), thereby decreasing its bioavailability and inducing systemic vasoconstriction; and (2) a direct toxicity of $\mathrm{fHb}$ that aggregates into casts in the tubular lumen [14, 15]. Better and earlier identification of haemolysis-related AKI may allow the selection of patients who could benefit from specific and innovative treatments such as intravenous haptoglobin administration [16]. The objective of this study was to evaluate the association between plasma haptoglobin level-a widely available biomarker of intravascular haemolysis-and occurrence of major adverse kidney events (MAKE) and AKI in critically ill burn patients.

\section{Methods}

\section{Study design and population}

We conducted a single-centre cohort study in the burn unit of St. Louis Hospital (Assistance Publique - Hôpitaux de Paris), Paris, France. The study was approved by our local ethics committee (PRONOBURN study, comité de protection des personnes IV, St-Louis Hospital; Institutional Review Board 00003835, protocol 2013/ 17NICB). All medical records of the patients admitted to our intensive care burn unit between January 2012 and April 2017 were screened. All burn patients meeting the following criteria were included in the study: total body surface area (TBSA) burned $>20 \%$, and/or mechanical ventilation at admission, and/or catecholamine infusion at admission, and a measurement of haptoglobin upon admission.

\section{Outcomes}

The primary endpoint of the study was MAKE at day 90. The secondary endpoints were AKI and death within 90 days. MAKE was defined as a composite of the following criteria: death within 90 days, new renal replacement therapy (RRT) during ICU stay, and/or no renal recovery (defined as a ratio of serum creatinine at ICU discharge to serum creatinine at admission > 125\%) [17]. AKI was defined and staged according to the Kidney Disease: Improving Global Outcomes criteria [17]. Serum creatinine (Screat) at hospital admission was used to define the baseline Screat.

\section{Measurements}

We collected the following data: age, sex, body mass index, TBSA, full-thickness body surface area burned, mechanism of injury and patient characteristics, Simplified Acute Physiology Score II (SAPS II), Abbreviated Burn Severity Index (ABSI) [18], Unit Burn Standard [19], treatments administered during the first 7 days after admission (hydroxocobalamin, aminoglycosides, vasopressors), and 28- and 90-day mortality. Haptoglobin measurement was performed using a haptoglobin assay (Hitachi modular P analyser; Roche, Paris, France) that is based on the principle of immunological agglutination. Anti-haptoglobin antibodies react with antigen in the sample to form antigen-antibody complexes, which, after agglutination, can be determined turbidimetrically. The reference values of haptoglobin are from $0.3 \mathrm{~g} / \mathrm{L}$ to $2 \mathrm{~g} / \mathrm{L}$; the detection limit is $0.1 \mathrm{~g} / \mathrm{L}$; and the linearity limit is $5.2 \mathrm{~g} / \mathrm{L}$.

\section{Patient management}

Patients were resuscitated according to the St. Louis Hospital Intensive Care Burn Unit resuscitation protocol with the following haemodynamic targets: mean arterial blood pressure $>65 \mathrm{mmHg}, 0.5 \mathrm{ml} / \mathrm{kg} / \mathrm{h}$ less than urine output $<1 \mathrm{ml} / \mathrm{kg} / \mathrm{h}, 2.5 \mathrm{~L} /$ minute $/ \mathrm{m}^{2}$ less than cardiac index $<3 \mathrm{~L} /$ minute $/ \mathrm{m}^{2}$ and central venous oxygen saturation $>70 \%$. Norepinephrine was administered when required (diastolic arterial blood pressure $<50 \mathrm{mmHg}$ and/ or systemic vascular resistance index $<1250 \mathrm{dyn} /$ second/ $\left.\mathrm{cm}^{-5} / \mathrm{m}^{2}\right)$. Patients received initial fluid resuscitation using an intravenous bolus of Ringer's lactate $0.25 \mathrm{ml} /$ $\mathrm{kg} / \% \mathrm{TBSA} / \mathrm{h}$ (which corresponds to the $2 \mathrm{ml} / \mathrm{kg} / \% \mathrm{TBSA}$ in the first $8 \mathrm{~h}$ of the Parkland formula) with fluid infusion adjusted to reach pre-defined haemodynamic targets. Cardiac function was systematically assessed on admission by echocardiography. Cardiac index was measured by transpulmonary thermodilution using a PiCCO2 monitor (Pulsion Medical Systems AG, Munich, Germany). The PiCCO monitor was calibrated every $2 \mathrm{~h}$ during the first $48 \mathrm{~h}$.

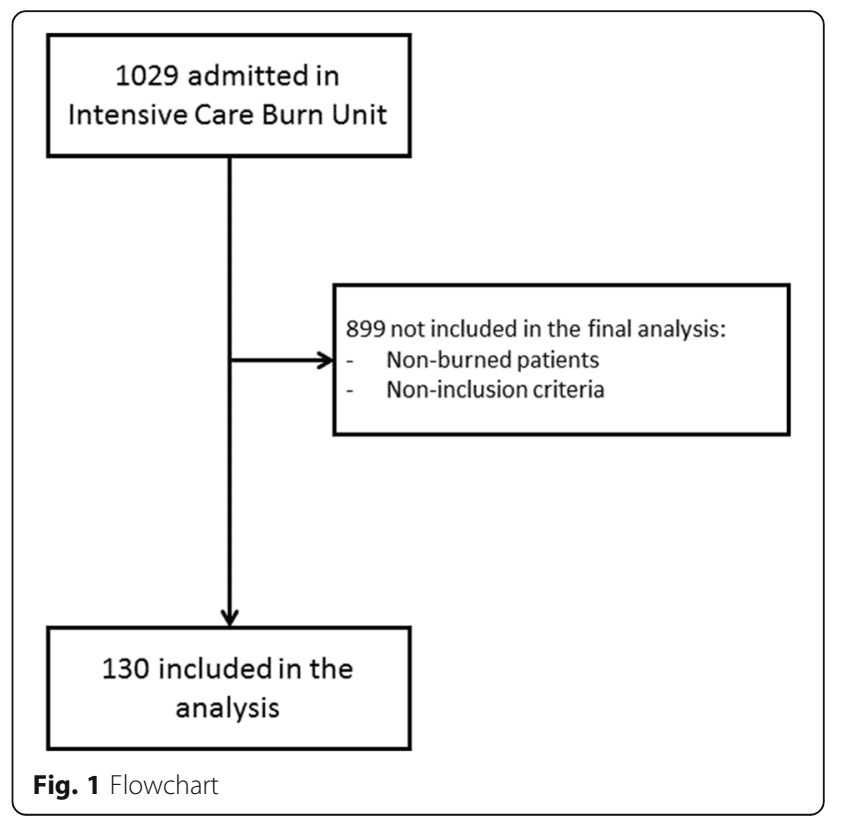


Albumin 20\% was administered to patients with TBSA $>30 \%$ after the sixth hour after thermal injury to reach a serum albumin concentration of 30-35 g/L. When mechanical ventilation was initiated, tidal volume was limited to 6-7 $\mathrm{ml} / \mathrm{kg}$ to maintain an inspiratory plateau pressure $<30 \quad \mathrm{cmH}_{2} \mathrm{O}$ and a transpulmonary driving pressure $<15 \mathrm{cmH}_{2} \mathrm{O}$. Early enteral nutrition was initiated within $24 \mathrm{~h}$ of admission. Glycaemic control was adjusted to maintain glucose levels between 5 and $9 \mathrm{mmol} / \mathrm{L}$. Surgical treatment included escharotomy or fasciotomy as needed and early coverage of excised burn wounds with autografts and/or allografts within the first 7 days after admission.

\section{Statistical analysis}

Continuous variables are reported as mean and SD or median (25th-75th percentile range) as appropriate. Categorical variables are expressed as count (percent). Categorical variables were compared using the chisquare test or Fisher's exact test as appropriate. Continuous variables were compared using Student's $t$ test or the Mann- Whitney $U$ test as appropriate.

Variables associated with MAKE and AKI in univariate analysis were entered in a multivariable logistic regression model with Lasso penalization [20] to identify the factors independently associated with the outcome. Inference was obtained using the post-selection

Table 1 Patient characteristics

\begin{tabular}{|c|c|c|c|c|}
\hline & All patients $(n=130)$ & $\operatorname{MAKE}(n=41)$ & No MAKE $(n=89)$ & $p$ Value \\
\hline Age, years & $48.5(34-61.8)$ & $53(47-67)$ & $44(29-58)$ & 0.02 \\
\hline \multicolumn{5}{|l|}{ Sex, $n(\%)$} \\
\hline Male & $80(61.5)$ & $24(58.5)$ & $56(62.9)$ & \multirow[t]{2}{*}{0.7} \\
\hline Female & $50(38.5)$ & $17(41.5)$ & $33(37.1)$ & \\
\hline $\mathrm{BMl}, \mathrm{kg} / \mathrm{m}^{2}$ & $25.1(22.7-28.5)$ & $26.2(22.8-30.6)$ & $24.9(22.7-27.5)$ & 0.06 \\
\hline \multicolumn{5}{|l|}{ Co-morbidities, n (\%) } \\
\hline Hypertension & $27(20.8)$ & $13(31.7)$ & $14(15.7)$ & 0.06 \\
\hline Diabetes mellitus & $16(12.3)$ & $8(19.5)$ & $8(9)$ & 0.15 \\
\hline Chronic kidney disease & $2(1.5)$ & $1(2.4)$ & $1(1.1)$ & 0.53 \\
\hline Vascular disease & $8(6.2)$ & $3(7.3)$ & $5(5.6)$ & 0.71 \\
\hline Obesity & $21(16.1)$ & $12(29.3)$ & $9(10.1)$ & 0.01 \\
\hline Smoking & $14(10.8)$ & $2(4.9)$ & $12(13.5)$ & 0.22 \\
\hline Alcohol consumption & $15(11.5)$ & $5(12.2)$ & $10(11.2)$ & 1 \\
\hline Psychiatric & $17(13.1)$ & $6(14.6)$ & $11(12.4)$ & 0.78 \\
\hline \multicolumn{5}{|l|}{ Burn type, $n(\%)$} \\
\hline Thermal & $123(94.6)$ & $41(100)$ & $82(92.1)$ & \multirow[t]{2}{*}{0.1} \\
\hline Electrical & $7(5.4)$ & $0(0)$ & $7(7.9)$ & \\
\hline \multicolumn{5}{|l|}{ Body surface area burned (\%) } \\
\hline Total & $28.5(15-50.8)$ & $50(22.5-70)$ & $20(12-40)$ & $<0.0001$ \\
\hline Full thickness & $15(4-32.2)$ & $25(15-56)$ & $8(1.8-25)$ & $<0.0001$ \\
\hline ICU length of stay, days & $27.5(10-42.5)$ & $18(3-38)$ & $29(13.2-45)$ & 0.42 \\
\hline Death in ICU, $n(\%)$ & $33(25.4)$ & $33(80.5)$ & $0(0)$ & $<0.0001$ \\
\hline Day of death & $15(3-32)$ & $15(3-32)$ & - & \\
\hline SAPS ॥ & $33(19-49)$ & $45(35-72)$ & $24(15-39)$ & $<0.0001$ \\
\hline UBS & $67(24-146)$ & $110(65-224)$ & $46(16-113)$ & $<0.0001$ \\
\hline ABSI & $8(6-10)$ & $11(8-12)$ & $7(5-9)$ & $<0.0001$ \\
\hline Serum creatinine on admission, $\mu \mathrm{mol} / \mathrm{L}$ & $67(65-113)$ & $88(67-118)$ & $64(54-77)$ & $<0.0001$ \\
\hline Maximal blood lactate concentration within 7 days, $\mathrm{mmol} / \mathrm{L}$ & $4.3(2.8-7)$ & $7(5.2-9.4)$ & $3.2(2.2-4.7)$ & $<0.0001$ \\
\hline Minimal serum haptoglobin level, g/L & $0.6(0.1-1.2)$ & $0.1(0.1-0.5)$ & $0.8(0.5-1.4)$ & $<0.0001$ \\
\hline Undetectable haptoglobin level, $n$ (\%) & $39(30)$ & $28(68.3)$ & $11(12.4)$ & $<0.0001$ \\
\hline
\end{tabular}

Abbreviations: BMI Body Mass Index, ICU Intensive Care Unit, SAPS II Simplified Acute Physiology Score II, UBS Unit Burn Standard, ABSI Abbreviated Burn Severity Index

Data are expressed as median \pm 25 th-75th interquartile range for continuous variables and count (percent) for discrete variables 
inference method for $L_{1}$-penalized models described by Taylor and Tibshirani [21]. Considering the rule of thumb suggesting at least five to ten events for each predictor variable included in the model [22], only the most clinically relevant were included in the multivariate model: creatinine at admission, SAPS II, ABSI, undetectable haptoglobin, need for catecholamine during the first 7 days, and administration of hydroxocobalamin. Model performance was estimated using the cross-validated (tenfold) AUC. Mortality during the first 90 days was described using the Kaplan-Meier estimate and modelled using a Cox proportional hazards model. Survival curves were compared using the logrank test. In all comparisons, a $p$ value $<0.05$ was considered statistically significant. All analyses were performed using $\mathrm{R}$ software version 3.3.3 for Mac ( $\mathrm{R}$ Foundation for Statistical Computing, Vienna, Austria).

\section{Results}

\section{Study population}

Between January 2012 and April 2017, 1029 patients were admitted (Fig. 1). Of these, 899 did not meet the inclusion criteria. The characteristics of the 130 patients included in the study are summarised in Table 1.

\section{Outcomes}

Forty-one patients developed MAKE, including 33 (80.5\%) patients who died within 90 days. Twenty-six patients required RRT, and 25 patients had no renal recovery. Seventy-three patients developed AKI during the first 7 days, including 29 (39.7\%) patients with stage 1 AKI, 17 (23.3\%) with stage 2 and 27 (37\%) with stage 3 AKI (Table 2). Only one patient developed AKI after 7 days. Among the 73 patients who developed AKI during the first 7 days, $32(44 \%)$ died during their ICU stay.

\section{Haptoglobin and outcomes}

Undetectable plasma haptoglobin was observed in $39 \mathrm{pa}-$ tients (30\%) at ICU admission. All but one had a total burned surface area $>20 \%$. Of these 39 patients, 34 (87.2\%) developed AKI and 29 (74.4\%) developed MAKE. The minimal haptoglobin concentration was significantly lower in patients with MAKE than in patients without ( $p=0.002)$ (Fig. 2). The frequency of MAKE by haptoglobin quintile is illustrated in Fig. 3.

In univariate analysis, undetectable haptoglobin was strongly associated with MAKE (OR 15.27, 95\% CI 6.34-39.66, $p<0.001)$. In multivariate analysis, undetectable haptoglobin (OR 8.32, 95\% CI 2.86-26.40, $p<0.001$ ), admission creatinine (OR $1.02,95 \% \mathrm{CI}$ 1.00-1.03, $p=0.05)$, need for catecholamine during the first 7 days (OR 4.71, 95\% CI 1.54-15.49, $p=0.01$ ) and SAPS II score (OR 1.04, 95\% CI 1.01-1.07, $p=$ $0.02)$ were independently associated with MAKE (Table 3) (model discrimination AUC 0.88, 95\% CI 0.80-0.96).

After adjustment, admission creatinine (OR 1.02, 95\% CI 1.00-1.03, $p=0.05$ ), SAPS II (OR 1.04, 95\% CI 1.01-1.07, $p=0.02$ ), shock within 7 days (OR 4.71, 95\% CI 1.54-15.49, $p=0.01)$ and undetectable

Table 2 Renal outcomes

\begin{tabular}{|c|c|c|c|c|}
\hline & All patients $(n=130)$ & $\operatorname{MAKE}(n=41)$ & No MAKE $(n=89)$ & $p$ Value \\
\hline \multicolumn{5}{|l|}{ Kidney aggression factors within 7 days, $n$ (\%) } \\
\hline Aminoglycoside & $5(3.9)$ & $5(12.2)$ & $0(0)$ & 0.0026 \\
\hline Hydroxocobalamin & $24(18.5)$ & $14(34.1)$ & $10(11.2)$ & 0.0031 \\
\hline Shock (use of catecholamine) & $58(44.6)$ & $34(82.9)$ & $24(27)$ & $<0.0001$ \\
\hline AKI within 7 days, $n(\%)$ & $73(56.1)$ & $39(95.1)$ & $34(38.2)$ & $<0.0001$ \\
\hline KDIGO stage of patients with AKI within 7 days & $2(1-3)$ & $3(2-3)$ & $1(1-2)$ & $<0.0001$ \\
\hline \multicolumn{5}{|l|}{ Serum creatinine, $\mu \mathrm{mol} / \mathrm{L}$} \\
\hline Admission & $67(54-90)$ & $88(67-118)$ & $64(54-77)$ & $<0.0001$ \\
\hline Maximum within 7 days & $80(65-113)$ & $135(85-206)$ & $74(64-86)$ & $<0.0001$ \\
\hline ICU discharge (alive, without RRT) & $49(35-63)$ & $64(43-85)$ & $49(35-61)$ & 0.07 \\
\hline Oliguria within 7 days, $n(\%)$ & $63(48.5)$ & 35 (85.4) & $28(31.5)$ & $<0.0001$ \\
\hline \multicolumn{5}{|l|}{ RRT $n(\%)$} \\
\hline Within 7 days & $18(13.8)$ & $18(44)$ & $0(0)$ & $<0.0001$ \\
\hline During ICU stay & $26(20)$ & $26(63.4)$ & $0(0)$ & $<0.001$ \\
\hline Alive at ICU discharge & $1(0)$ & $1(2.4)$ & - & \\
\hline
\end{tabular}

Abbreviations: AKI Acute kidney injury, KDIGO Kidney Disease Improving Global Outcomes, ICU Intensive care unit, RRT Renal replacement therapy Data are expressed as median \pm 25 th -75 th interquartile range for continuous variables and number (percent) for discrete variables 


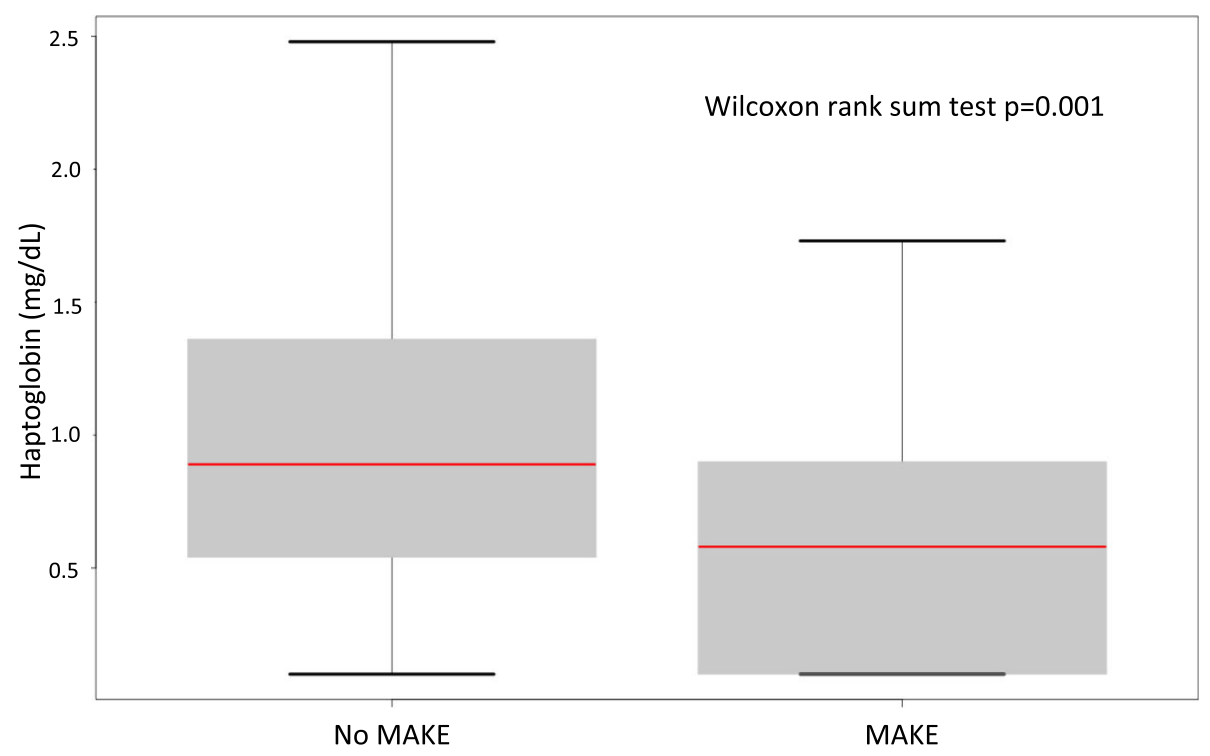

Fig. 2 Box plot displaying minimal haptoglobin level between major adverse kidney events (MAKE) and no MAKE

haptoglobin (OR 8.32, 95\% CI 2.86-26.40, $p<0.001$ ) were independently associated with the occurrence of AKI. In patients with undetectable haptoglobin, the risk of death during the first 90 days was higher $(23$ [59\%] of 39 versus 9 [10\%] of 91; $p<0.0001$ ) (Fig. 4). This remained true after adjusting on severity (HR 5.11, 95\% CI 2.21-11.78, $p<0.001$ ).

\section{Factors associated with undetectable haptoglobin}

In multivariable analysis, TBSA was independently associated with undetectable haptoglobin (OR 1.04, 95\% CI 1.00-1.07, $p=0.03$ ), whereas ABSI, smoke inhalation and SAPS II were not (respectively, OR 1.16,
95\% CI $0.89-1.5, p=0.27$; OR $1.88,95 \%$ CI $0.72-4.95$, $p=0.20$; and OR 1.01, 95\% CI 0.98-1.03, $p=0.54$ ).

\section{Discussion}

We observed $30 \%$ of undetectable plasma haptoglobin in our cohort of critically ill burn patients. The main finding of this study is that undetectable haptoglobin on admission after burn injury is strongly and independently associated with the occurrence of MAKE, AKI and 90-day mortality in critically ill burn patients.

The association between haemolysis and AKI after major aortic surgery [12] and in sickle cell disease [11] has already been described. This is the first

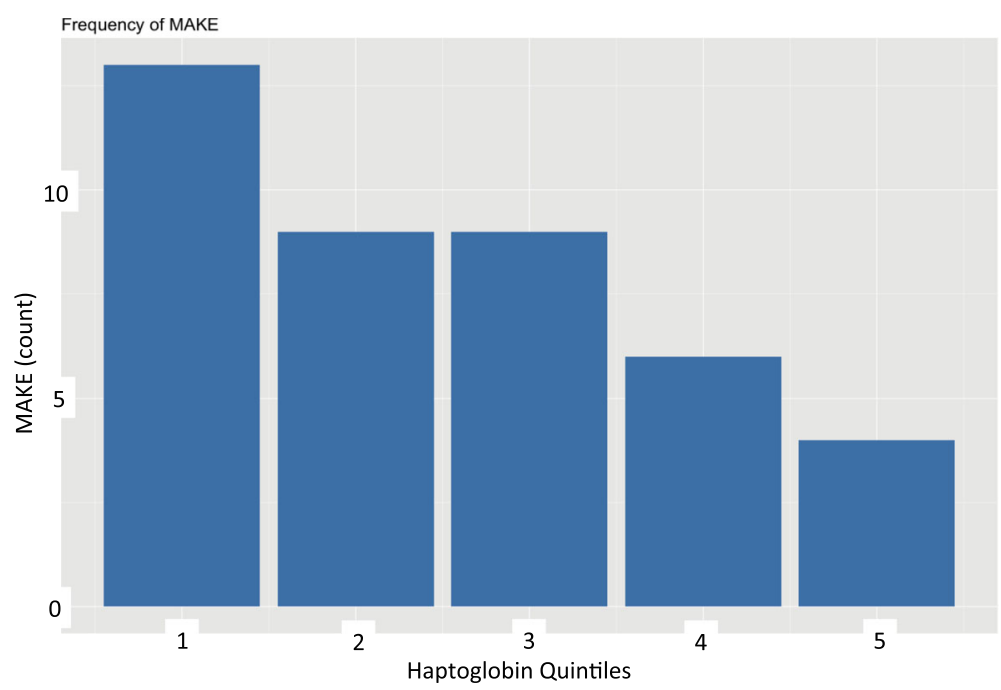

Fig. 3 Major adverse kidney event (MAKE) count by haptoglobin quintiles 
Table 3 Multivariable Lasso penalized logistic model: variables associated with major adverse kidney events

\begin{tabular}{llll}
\hline Variable & OR & $95 \% \mathrm{Cl}$ & $p$ Value \\
\hline Admission creatinine & $1.02 / \mu \mathrm{mol} / \mathrm{L}$ & $1.00-1.03$ & 0.03 \\
SAPS II & $1.03 / 1$ point & $1.00-1.06$ & 0.05 \\
ABSI & $1.14 / 1$ point & $0.88-1.35$ & 0.19 \\
Shock in the first 7 days & 4.18 & $1.44-10.59$ & 0.02 \\
Haptoglobin undetectable & 6.33 & $2.34-16.45$ & $<0.001$ \\
\hline
\end{tabular}

SAPS II Simplified Acute Physiology Score II, ABSI Abbreviated Burn Severity Index

study, to our knowledge, describing the association between haptoglobin level and MAKE or AKI in a population of critically ill burn patients. In 1943, Shen et al. [8] described a $25 \%$ incidence of haemolysis in 40 patients with combined second-degree and third-degree thermal burns over $15-65 \%$ of the body area. Eleven patients developed haemolysis as evidenced by the presence of haemoglobinuria. In the literature on thermal burns, haemolysis is infrequently reported as a complication of severe third-degree burns [8]. In the present study, $38(>97 \%)$ of 39 cases with undetectable haemolysis had $>20 \%$ TBSA. TBSA was strongly associated with undetectable haptoglobin, even after adjustment for confounding factors. Physiopathology of renal toxicity of haemolysis is probably multifactorial, including (1) the role of the fHb azote monoxide (NO) scavenger, decreasing its bioavailability and therefore inducing systemic vasoconstriction; and (2) direct toxicity of $\mathrm{fHb}$ aggregating into casts in the tubular lumen $[14,15]$.

We describe a high incidence of AKI in the first week (56\%), which is close to the incidence reported by Palmieri et al., who described an incidence of $53 \%$ in a retrospective cohort of 60 severely burned patients ( $>20 \%$ TBSA) [3]. In their study, they did not describe the prevalence of MAKE; however, AKI was strongly associated with mortality because $34 \%$ of patients with AKI died, whereas no deaths were reported among patients without AKI. In the present study, we chose to use MAKE as the primary endpoint [17]. Of note, MAKE were driven largely by RRT and mortality in our cohort. Moreover, the prognosis of patients needing RRT was very poor, with a 90-day mortality of $78 \%$, which is again in accord with the available literature. Yoon et al. recently reported $84 \%$ mortality in burn patients receiving RRT [23].

Recently, in a single-centre, retrospective, observational Japanese study, intra-operative administration of haptoglobin was independently associated with a lower risk of AKI after cardiovascular surgery [16], suggesting a protective role of haptoglobin in binding $\mathrm{fHB}$ and therefore preventing its potential toxicity on the kidney. As far as we know, the use of haptoglobin in burn patients has been described only in a case report [24] of a 24-year-old man with
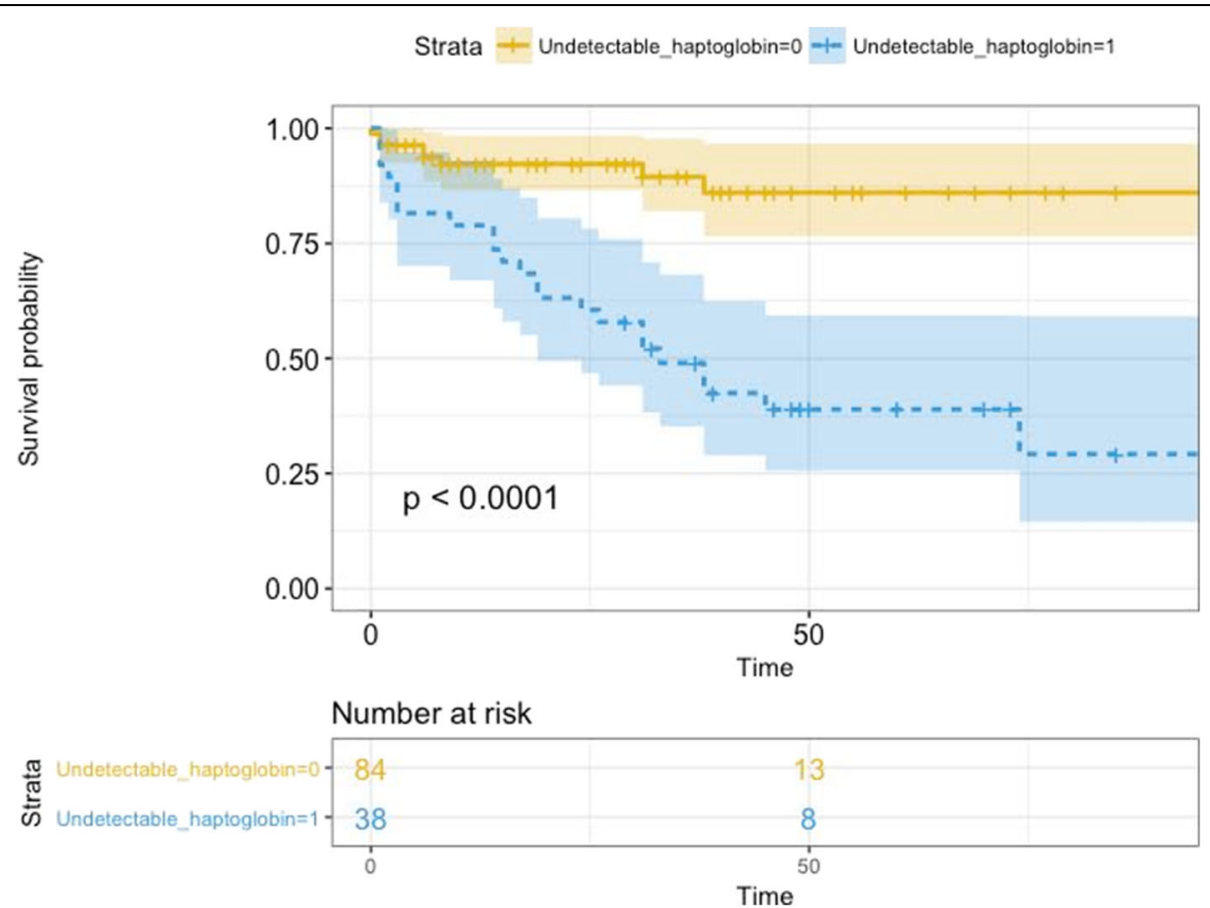

Fig. 4 Kaplan-Meier curve between patients with detectable and undetectable haptoglobin in the 72 first $h$ 
$100 \%$ TBSA and in a series of five patients [25]. In the case report, haptoglobin was administered three times over the first $24 \mathrm{~h}$ after the detection of haemoglobinuria. Despite the severity of the initial burn, the patient did not develop AKI in the five 5 days, suggesting a protective effect of intravenous haptoglobin administration [24].

Our study has some limitations. First, this was an observational study, and thus it describes an association between haemolysis, MAKE and AKI, but not necessarily a causal relationship. Second, it was a single-centre study. This may limit the generalisability of the results. However, our results rely on a strong pathophysiological background and may open a window for establishing methods to prevent MAKE and AKI in this population. Third, low haptoglobin level could arise from conditions other than haemolysis. However, the differential diagnoses appear to be very unlikely in our population. Haptoglobin was measured upon admission, before hepatic dysfunction occurs in critically ill patients. Finally, even though burn patients are frequently transfused after surgery for excision, none were transfused in the early phase (first $96 \mathrm{~h}$ ), and none had associated trauma or haemorrhage.

\section{Conclusions}

This study shows that undetectable haptoglobin was strongly associated with the development of MAKE, AKI and 90-day mortality in a large cohort of patients with severe burns. Further multicentre studies should be performed to confirm these results. Interventional studies using recombinant haptoglobin should be considered in the future to improve outcome in patients with severe burns.

\section{Abbreviations \\ ABSI: Abbreviated Burn Severity Index; AKl: Acute kidney injury; BMI: Body mass index; fHb: Cell-free haemoglobin; ICU: Intensive care unit; KDIGO: Kidney Disease: Improving Global Outcomes; MAKE: Major adverse kidney event; RRT: Renal replacement therapy; SAPS II: Simplified Acute Physiology Score II; Screat: Serum creatinine; TBSA: Total body surface area; UBS: Unit Burn Standard}

\section{Acknowledgements}

None.

\section{Funding}

None.

\section{Availability of data and materials}

The datasets used and/or analysed during the present study are available from the corresponding author on reasonable request.

\section{Authors' contributions}

FD collected data, performed analysis and interpretation of the data, and drafted the manuscript. CD collected data and contributed to interpretation of the data as well as to drafting the manuscript. CDT collected data and contributed to interpretation of the data as well as to drafting the manuscript. MChau collected data and contributed to interpretation of the data as well as to drafting the manuscript. $A B$ contributed to interpretation of the data and to drafting the manuscript. AF collected data and contributed to interpretation of the data as well as to drafting the manuscript. NM performed haptoglobin dosage and contributed to interpretation of the data as well as to drafting the manuscript. AC collected data and contributed to interpretation of the data as well as to drafting the manuscript. SS collected data and contributed to interpretation of the data as well as to drafting the manuscript. MB collected data and contributed to interpretation of the data as well as to drafting the manuscript. AM conceived of the study and contributed to interpretation of the data as well as to drafting the manuscript. KS collected data and contributed to interpretation of the data as well as to drafting the manuscript. MChao collected data and contributed to interpretation of the data as well as to drafting the manuscript. JPG performed haptoglobin dosage and contributed to interpretation of the data as well as to drafting the manuscript. RP performed the statistical analysis and supervised the interpretation of the data as well as the drafting of the manuscript. ML conceived of the study, performed interpretation of the data and drafted the manuscript. All authors read and approved the final manuscript.

\section{Ethics approval and consent to participate}

The study was approved by our local ethics committee (PRONOBURN study, comité de protection des personnes IV, St-Louis Hospital; Institutional Review Board 00003835, protocol 2013/17NICB). Informed consent was waived by the ethics committee for this study.

\section{Consent for publication}

Not applicable.

\section{Competing interests}

The authors declare that they have no competing interests.

\section{Publisher's Note}

Springer Nature remains neutral with regard to jurisdictional claims in published maps and institutional affiliations.

\section{Author details}

${ }^{1}$ Department of Anesthesiology and Critical Care and Burn Unit, Groupe Hospitalier St-Louis-Lariboisière, Assistance publique - Hôpitaux de Paris, Paris, France. ${ }^{2}$ Université Paris Diderot, Paris, France. ${ }^{3}$ Service de Biochimie, Hôpital universitaire St-Louis, 1 avenue Claude Vellefaux, Paris 75010, France. ${ }^{4}$ UMR INSERM 942, Institut National de la Santé et de la Recherche Médicale (INSERM), French Clinical Research Infrastructure Network (F-CRIN) Investigation Network Initiative-Cardiovascular and Renal Clinical Trialists (INI-CRCT network), Paris, France. ${ }^{5}$ Hôpital Européen Georges Pompidou, 20 rue Leblanc, Paris 75015, France. ${ }^{6}$ Service de Biostatistique et Informatique Médicale, INSERM UMR-1153, Equipe ECSTRA, Hôpital Saint Louis, Sorbonne Paris Cité, Paris, France. ${ }^{7}$ French Clinical Research Infrastructure Network (F-CRIN) Investigation Network Initiative-Cardiovascular and Renal Clinical Trialists (INI-CRCT network), Paris, France.

Received: 2 August 2017 Accepted: 7 September 2017 Published online: 26 September 2017

\section{References}

1. Dennen P, Douglas IS, Anderson R. Acute kidney injury in the intensive care unit: an update and primer for the intensivist. Crit Care Med. 2010;38:261-75.

2. Clec'h C, Gonzalez F, Lautrette A, Nguile-Makao M, Garrouste-Orgeas M, Jamali $\mathrm{S}$, et al. Multiple-center evaluation of mortality associated with acute kidney injury in critically ill patients: a competing risks analysis. Crit Care. 2011;15:R128.

3. Palmieri T, Lavrentieva A, Greenhalgh DG. Acute kidney injury in critically ill burn patients: risk factors, progression and impact on mortality. Burns. 2010:36:205-11.

4. Emara SS, Alzaylai AA. Renal failure in burn patients: a review. Ann Burns Fire Disasters. 2013;26:12-5

5. Clark A, Neyra JA, Madni T, Imran J, Phelan H, Arnoldo B, et al. Acute kidney injury after burn. Burns. 2017;43:898-908.

6. Mason SA, Nathens AB, Finnerty CC, Gamelli RL, Gibran NS, Arnoldo BD, et al. Hold the pendulum: rates of acute kidney injury are increased in patients who receive resuscitation volumes less than predicted by the Parkland equation. Ann Surg. 2016;264:1142-7. 
7. Wu G, Xiao Y, Wang C, Hong X, Sun Y, Ma B, et al. Risk factors for acute kidney injury in patients with burn injury: a meta-analysis and systematic review. J Burn Care Res. 2017;38:271-82.

8. Shen SC, Ham TH, Fleming EM. Studies on the destruction of red blood cells: mechanism and complications of hemoglobinuria in patients with thermal burns: spherocytosis and increased osmotic fragility of red blood cells. N Engl J Med. 1943;229:701-13.

9. Siah S, Elmaataoui A, Messaoudi N, Ihrai I, Kamili ND. The mechanism of non-immune haemolytic anaemia in burns patient [in French]. Ann Biol Clin (Paris). 2010;68:603-7.

10. Reiter CD, Wang X, Tanus-Santos JE, Hogg N, Cannon RO, Schechter AN, et al. Cell-free hemoglobin limits nitric oxide bioavailability in sickle-cell disease. Nat Med. 2002;8:1383-9.

11. Nath KA, Hebbel RP. Sickle cell disease: renal manifestations and mechanisms. Nat Rev Nephrol. 2015:11:161-71.

12. Windsant ICV, Snoeijs MG, Hanssen SJ, Altintas S, Heijmans JH, Koeppel TA, et al. Hemolysis is associated with acute kidney injury during major aortic surgery. Kidney Int. 2010;77:913-20.

13. Mamikonian LS, Mamo LB, Smith PB, Koo J, Lodge AJ, Turi JL. Cardiopulmonary bypass is associated with hemolysis and acute kidney injury in neonates, infants, and children. Pediatr Crit Care Med. 2014;15:e111-9.

14. Rother RP, Bell L, Hillmen P, Gladwin MT. The clinical sequelae of intravascular hemolysis and extracellular plasma hemoglobin: a novel mechanism of human disease. JAMA. 2005;293:1653-62.

15. Vermeulen Windsant IC, Hanssen SJ, Buurman WA, Jacobs MJ. Cardiovascular surgery and organ damage: time to reconsider the role of hemolysis. J Thorac Cardiovasc Surg. 2011;142:1-11.

16. Kubota K, Egi M, Mizobuchi S. Haptoglobin administration in cardiovascular surgery patients: its association with the risk of postoperative acute kidney injury. Anesth Analg. 2017;124:1771-6.

17. Kellum JA, Lameire N, Aspelin P, Barsoum RS, Burdmann EA, Goldstein SL, et al. KDIGO Clinical Practice Guideline for Acute Kidney Injury. Kidney Int Suppl. 2012;2:1.

18. Tobiasen J, Hiebert JM, Edlich RF. The Abbreviated Burn Severity Index. Ann Emerg Med. 1982:11:260-2

19. Bull JP, Squire JR. A study of mortality in a burns unit: standards for the evaluation of alternative methods of treatment. Ann Surg. 1949;130:160-73.

20. Tibshirani R. Regression shrinkage and selection via the lasso: a retrospective: regression shrinkage and selection via the lasso. J R Stat Soc Series B Stat Methodol. 2011;73:273-82.

21. Taylor J, Tibshirani R. Post-selection inference for $\ell_{1}$-penalized likelihood models. Can J Stat. doi:10.1002/cjs.11313.

22. Peduzzi P, Concato J, Kemper E, Holford TR, Feinstein AR. A simulation study of the number of events per variable in logistic regression analysis. J Clin Epidemiol. 1996;49:1373-9.

23. Yoon J, Kim Y, Yim H, Cho YS, Kym D, Hur J, et al. Analysis of prognostic factors for acute kidney injury with continuous renal replacement therapy in severely burned patients. Burns. 2017. doi:10.1016/..burns.2017.03.015.

24. Imaizumi H, Tsunoda K, Ichimiya N, Okamoto T, Namiki A. Repeated large-dose haptoglobin therapy in an extensively burned patient: case report. J Emerg Med. 1994;12:33-7.

25. Yoshioka T, Sugimoto T, Ukai T, Oshiro T. Haptoglobin therapy for possible prevention of renal failure following thermal injury: a clinical study. J Trauma. 1985;25:281-7.

\section{Submit your next manuscript to BioMed Central and we will help you at every step:}

- We accept pre-submission inquiries

- Our selector tool helps you to find the most relevant journal

- We provide round the clock customer support

- Convenient online submission

- Thorough peer review

- Inclusion in PubMed and all major indexing services

- Maximum visibility for your research

Submit your manuscript at www.biomedcentral.com/submit

Biomed Central 